\title{
The effect of FR response requirement on aggressive behavior in rats'
}

WILLIAM D. GENTRY and ROBERT W. SCHAEFFER, Florida State University, Tallahassee, Fla. 32306

Attack responses were observed in water-deprived rats that were exposed to $F R-20, F R-40$, and FR-60 water reinforcement schedules. Relative to the baseline condition, aggression increased under the FR-20 schedule. The frequency of attack behavior under the FR-40 and FR-60 conditions was equal to, or less than, the frequency of attack observed in the baseline condition. Attack responses were found to be equally probable in all segments of the interreinforcement intervals. These results were discussed with regard to the results of other studies of schedule-induced aggression.

Recent investigations have demonstrated that certain fixed-ratio (FR) schedules of reinforcement will act as elicitors of infrahuman aggression. Gentry (1968) has shown that an FR-50 schedule of food reinforcement produces high intensity attack behavior in pigeons. Hutchinson, Azrin, \& Hunt (1968) have reported that the frequency of aggressive biting responses in primates is directly related to the magnitude of the FR response requirement. Both Gentry (1968) and Hutchinson et al (1968) have suggested that the aggressive behavior exhibited under FR schedules may be associated with periodic presentation and withdrawal of food and, therefore, may be analogous to "extinction-induced" attack (Azrin, Hutchinson, \& Hake, 1966).

The present study was undertaken to examine the effects of increased response requirements on aggressive behavior for a different type of reinforcement (water) and a different species (rats) of animals than had been used by the Es cited above. METHOD

The Ss were eight experimentally-naive female SpragueDawley rats, approximately 120 days old at the beginning of the experiment. Four Ss were experimental animals; the other four served as target animals. Each target rat was assigned to a specific experimental animal and each pair of Ss was matched for weight. The experimental Ss were maintained on 23-h water deprivation; the target animals had water continually available in the home cages. All animals were housed in separate home cages with ad lib food available.

The apparatus consisted of a Grason-Stadler E3125B test chamber. The door of the test chamber enclosure was left open to permit an unobstructed view of the Ss. All programming of the FR reinforcement schedules was accomplished with standard electro-mechanical devices. A white-noise generator provided a continuous masking noise throughout the entire course of each experimental session.

Attack responses were defined and recorded on counters in the manner prescribed by Ulrich and Azrin (1962). Two Es independently depressed hand-operated microswitches to record aggressive behavior that occurred during any phase of the experiment. Inter- $O$ agreement on attack behavior consistently exceeded $96 \%$.

The procedure was carried out in four phases: a baseline or no-reinforcement condition, an FR-20 condition, an FR-40 condition, and an FR-60 condition. Each phase consisted of five $30-\mathrm{min}$ sessions. Thus, a total of 20 experimental sessions were given to each pair of rats. All test sessions were given daily.

During the initial period of no-reinforcement, each pair of animals was placed in the experimental chamber with the reinforcement mechanism inoperative. This baseline condition was used to provide a measure of aggressive behavior prior to the Ss having received any experience with $F R$ reinforcement schedules. Following the baseline condition, the target animal was not returned to the test chamber until the experimental $S$ had been trained to drink from a water dipper and shaped to press the response lever. The experimental Ss were initially reinforced on a CRF schedule, then subjected to progressively increasing ratio requirements. Stable responding on an FR-20 response requirement was achieved for all four experimental Ss within five days following the original shaping procedure. The target rat was then reintroduced into the test chamber for the second, and subsequent, phases of the experiment. After five sessions of the FR-20 requirement, the response requirement was increased to FR-40 for five sessions, then increased again, for five sessions, to FR-60.

\section{RESULTS}

Figure 1 shows the mean number of attack responses for each pair of Ss during all four phases of the experiment. Three of the four pairs of animals displayed the same pattern of aggression, the only difference between these Ss being in the relative amount of aggression exhibited. The behavior of Pair 4 differed from the other three pairs of Ss by showing little or no aggression throughout the entire experiment, except during one session of FR-60 reinforcement. Since no satisfactory explanation can be offered to account for the atypical behavior shown by Pair 4 , the following description of the animals' behavior will be limited to the three pairs of Ss that did consistently exhibit aggressive behavior.

During the baseline (i.e., no-reinforcement) condition, the experimental rats exhibited a moderate amount of aggression toward the target animals. The aggressive behavior was accompanied by noticeable incidences of exploratory behavior, grooming behavior, and general body contact. Attack behaviors occurred primarily during the first session of the baseline condition, then decreased across subsequent baseline sessions.

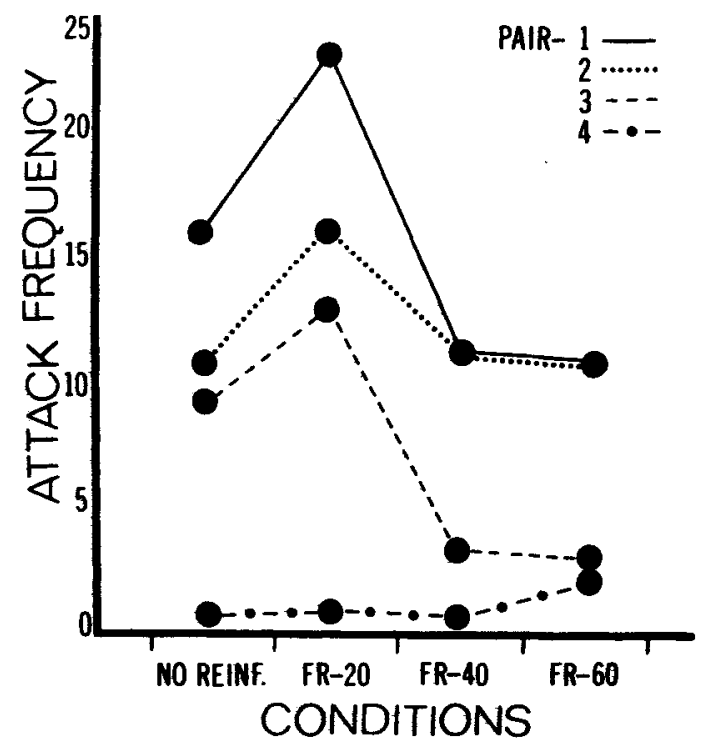

Fig. 1. Mean number of attack responses for the four pairs of $S s$ in all four phases of the experiment: baseline (i.e., no-reinforcement), FR-20, FR-40, FR-60.

(Contimued on page 238) 
ance responses in 50-trial blocks are presented for both groups in Fig. 1.

Subjects in the experimental group received significantly fewer shocks per escape trial $(F=7.34$, $\mathrm{df}=1 / 8, \mathrm{p}<.05)$ than did those in the control group. Fig. 2 shows the mean number of shocks received per discontinuous US escape trial in 50-trial blocks for both groups. Mean number of shocks per escape response may be considered a measure approximating escape response latency to discontinuous shock.

Avoidance performance is clearly unrelated to S's opportunity to execute escape responses in off-shock periods but appears to be related to escape response latency. Our analysis of the conditions producing the superior avoidance performance exhibited by Ss in the experimental group in this study is as follows: Presentation of discontinuous shock for half the escape trials served to eliminate freezing behaviors incompatible with efficient escape responding. Presentation of continuous shock on half the escape trials (a) served to shorten the latency of escape responses, and (b) provided a more favorable reinforcement contingency in which the US was terminated by the escape response.

\section{REFERENCES}

D'AMATO, M. R., KELLER, D., \& DiCARA, L. Facilitation of discriminated avoidance learning by discontinuous shock. Journal of Comparative \& Physiological Psychology, 1964, 58, 344-349.

HESS, J. H., \& SHAFER, J. N. Discontinuous shock and generalization to the preshock period in discriminated avoidance learning. Psychonomic Science, 1968, 10, 175-176.

HESS, J. H., \& SHAFER, J. N. Escape response distribution and discriminated avoidance of discontinuous shock. Psychonomic Science, 1968, 11, 255-256.

\section{NOTE}

1. Supported in part by United States Public Health Service Grant MH $11634-02$.

(Continued from page 236)

Relative to the baseline condition, a marked increase in the frequency of aggressive behavior occurred during the FR-20 reinforcement schedule sessions. The attacks that occurred in these sessions were not associated with any particular segment of the FR response sequence, such as the postreinforcement pause (Gentry, 1968; Hutchinson et al, 1968).

Relative to the FR-20 condition, an obvious decrease in aggressive behavior occurred during the FR-40 and FR-60 conditions. Under the FR-40 and FR-60 conditions, the experimental Ss spent more time pressing the response lever for reinforcement and less time in aggressive, exploratory, grooming, and general body contact behaviors than they had in the FR-20 condition. As is obvious from Fig. 1, there was little difference in the incidence of attack for the FR-40 and FR-60 conditions. As was the case in the FR-20 condition, aggressive responses under FR-40 and FR-60 were unrelated to any specific segment of the FR response sequence.

The changes in aggressive behavior across the various phases of the experiment were evaluated by a Treatment by Ss repeated-measures analysis of variance. The main effect of the FR schedule requirement was significant at the .01 level $(F=6.53, \mathrm{df}=3 / 73)$. $T$ tests indicated that the incidence of attack was greater for the FR-20 condition than for all other conditions $(t=2.45$, $\mathrm{df}=73, \mathrm{p}<.05)$. No significant differences were obtained, however, between the baseline, FR-40, and FR-60 conditions $(p>.10)$.

\section{DISCUSSION}

The results of the present study apparently confirm the generality of the FR schedule-induced aggression data obtained by Gentry (1968) and Hutchinson et al (1968). Relative to the baseline period, the increase in aggression under the FR-20 condition in the present study indicates that rats exposed to an FR schedule of water reinforcement show the same general increase in attack behavior that has been observed in pigeons and primates that earn food reinforcement under FR instrumental response requirements. The present results differ from previous reports on schedule-induced aggression, however, both with respect to the relationship between attack frequency and the magnitude of the FR requirement, and with respect to the primary location of attack behavior in the FR response sequence. With regard to the first issue, Hutchinson et al (1968) found that the frequency of an aggressive biting response in primates increased as the FR requirement increased. By comparison, the present results suggest that aggression shows an initial increase, then a marked decrease as the $F R$ requirement for water reinforcement is progressively raised to higher values. With regard to the second issue, both Gentry (1968) and Hutchinson et al (1968) reported that the greatest incidence of aggressive behavior occurs during the postreinforcement pause and during the early segments of the FR response run. The present data, however, suggest that the attack response, when it does occur, is equally probable at any temporal point in the interreinforcement interval. Additional research in this area would seem to be warranted to determine whether the present results are primarily attributable to species differences in aggressive behavior, or associated with differential effects of differing reinforcers (e.g., food vs water) on aggressive behavior.

\section{REFERENCES}

AZRIN, N. H., HUTCHINSON, R. R., \& HAKE, D. F. Extinctioninduced aggression. Journal of the Experimental Analysis of Behavior, 1966, 9, 191-204.

GENTRY, W. D. Fixed-ratio schedule-induced aggression. Journal of the Experimental Analysis of Behavior, 1968, 11, 813-817.

HUTCHINSON, R. R., AZRIN, N. H., \& HUNT, G. M. Attack produced by intermittent reinforcement on a concurrent operant response. Journal of the Experimental Analysis of Behavior, 1968, 11, 489-495.

ULRICH, R. E., \& AZRIN, N. H. Reflexive fighting in response to aversive stimulation. Journal of the Experimental Analysis of Behavior, 1962, 5, 511-520.

\section{NOTE}

1. This research was supported in part by Grants MH-08775 and MH-12025 from the National Institutes of Health, Robert W. Schaeffer, principal investigator. 